methods for symmetric and unsymmetric (real and complex) matrices, an economic Givens-type method for symmetric band matrices, similarity reduction to Hessenberg form, inverse iteration, norm-reducing Jacobi-type (real and complex) methods, the symmetric $A x=\lambda B x$ problem, and something on a priori matrix "balancing".

Iterative methods for linear systems are excluded because they arise mainly in connexion with other special problems, and the QZ algorithm for the generalized $\mathrm{Ax}=\lambda \mathrm{Bx}$ problem has been developed too late for inclusion. Otherwise the selection deliberately includes the "best" from the point of view of applicability, economy and accuracy, and it would be hard to see how the space could better be used.

The book is invaluable for computing services and for the practitioner who wants a guaranteed program for a particular purpose. But it also contains a wealth of information about the "how", "why" and "what" of numerical linear algebra, and represents a fine start to this very important series. L. Fox

\section{Language No Barrier}

Chemistry Through the Language Barrier: How to Scan Chemical Articles in Foreign Languages with Emphasis on Russian and Japanese. By Emmet Reid. Pp. ix +138 . (Johns Hopkins: Baltimore, May 1970.) £2.

THIS remarkable paperback has been written by a veteran chemist who is Professor Emeritus of Chemistry at the
Johns Hopkins University and lays no claim to linguistic proficiency. Indeed, his approach to the rather complex and not inconsiderable problem of the language barrier is summed up in his own words: "I am no linguist; German and French are the only languages I studied; in other languages I just picked up the information". His solution is to use his expert subject knowledge to steer him through a foreign language paper, or as he puts it: "If you want to read Czech, study your chemistry!"

To a linguist some of these statements and the very philosophy must seem strange and somewhat unprofessional since the perhaps insignificant looking words such as "not" or "but" or "however" - or rather their foreign language equivalents - may be easily overlooked in between the chemical terms. But of course the book is not so much concerned with translation as with scanning, that is to determine whether a foreign language original requires subsequent proper and professional translation or not. In this manner the author deals with a whole range of languages such as Italian, French, Dutch, Swedish, Danish, Norwegian, German, Hungarian, Finnish, Czech, Spanish, Romanian, Polish, Russian and Japanese. The author's method of dealing with the Cyrillic alphabet and the Japanese scripts (both Katakana and Hirakana) is ingenious though not very convincing since it relies largely on prior transcription into the Latin alphabet.

Perhaps the real value of this work lies, firstly, in the ease with which the argument is promoted that foreign languages are not really so very difficult to master, and, secondly, in the numerous glossaries and vocabularies which make up more than half of the slim volume.

Felix Liebesny

\section{Effect of Lasers}

Effects of High Power Laser Radiation. By John F. Ready. Pp. xii +433. (Academic: New York and London, October 1971.) $\$ 17.50$; $£ 8.15$.

DR READY, who was one of the very first investigators of the effects of laser radiation on solid targets, has written a most useful book which surveys a wide range of the effects due to intense light and describes many practical applications. The non-linear effects observed with very high power lasers are excluded from consideration. Introductory chapters on the properties of lasers and how to measure their output parameters are followed by descriptions of many of the effects of intense light. There are chapters on heating, ionization, plasma production, gas breakdown, damage in transparent materials and effects on biological systems, which give details of many experiments and discuss the results in the light of theoretical models. Finally, there is a very useful chapter on applications of these effects, which contains much practical information of particular value to engineers involved with machining and metalworking. Copious references and many illustrations are provided, with a fairly adequate subject index. The book is generally well produced, though pages 395-402 were absent in the review copy. The subject is developing rapidly, and I am sure Dr Ready will soon be asked for a second edition. T. P. Hughes

\section{HOW TO BUY NATURE}

Volumes start in January, March, May, July, September and November, but subscriptions may begin at any time.

The direct postal price per subscription is:

12 MONTHS (52 issues per title)

$\begin{array}{lcc} & \begin{array}{c}\text { Surface mail } \\ \text { UK and } \\ \text { worldwide }\end{array} & \begin{array}{c}\text { U.S.A. and } \\ \text { Canada }\end{array} \\ \begin{array}{l}\text { Nature (Friday) } \\ \begin{array}{l}\text { Nature + } \\ \text { Nature Physical Science }\end{array}\end{array} & £ 24 & \$ 48 \\ \begin{array}{l}\text { Nature + } \\ \text { Nature New Biology }\end{array} & £ 24 & \$ 83 \\ \text { All three editions } & £ 29.50 & \$ 108 \\ \text { Annual Index } & £ 1 & \$ 3\end{array}$

(Charge for delivery by air mail on application)
Editorial, Advertising and Publishing Offices of NATURE

MACMILLAN JOURNALS LIMITED

4 LITTLE ESSEX STREET, LONDON WC2R 3LF

Telephone Number: 01-836 6633. Telegrams: Phusis London WC2R 3LF Telex 262024

MACMILLAN JOURNALS LIMITED

711 NATIONAL PRESS BUILDING

WASHINGTON DC 20004

Telephone Number: $202-7372355$. Telex 64280

International Advertisement Manager PETER R. KAVANAGH

MACMILLAN JOURNALS LIMITED

4 LITTLE ESSEX STREET, LONDON WC2R 3LF

Telephone Numbers: UK 01-836 6633. USA 202-737 2355

Subscription Department

MACMILLAN JOURNALS LIMITED

BRUNEL ROAD, BASINGSTOKE, HANTS

Telephone Number: Basingstoke 29242

Classified advertisements

T. G SCOTT \& SON, LIMITEO

1 CLEMENT'S INN, LONDON WC2A 2ED

Telephone Number: 01-242 6264/01-406 4743

Telegrams: Textualist London WC2A 2ED

Registered as a newspaper at the Post Office

Copyright (C) Macmillan Journals Limited, November 241972 